\title{
A six-arm olfactometer for analysing olfactory responses of Goniozus legneri Gordh (Hymenoptera: Bethylidae), the larval ectoparasitoid of carob moth
}

\author{
M. Aleosfoor, ${ }^{1}$ F. Ehteshami, ${ }^{2}$ L. Fekrat ${ }^{3}$ \\ ${ }^{1}$ Department of Plant Protection, College of Agriculture, Shiraz University, Shiraz; ${ }^{2}$ Department of \\ Plant Protection, College of Agriculture, Shiraz University, Shiraz; ${ }^{3}$ Department of Plant \\ Protection, Ferdowsi University of Mashhad, Mashhad, Iran
}

\begin{abstract}
The behavioural responses of Goniozus legneri were investigated in a six-arm olfactometer. Among the different odours examined, carob moth (Ectomyelois ceratoniae Zeller) frass elicited the highest olfactory responses, while Ephestisa larvae, which were less suitable hosts, elicited the lowest response. The different preferences to various odours suggest that Goniozus legneri can discriminate among suitable and less suitable insect hosts.
\end{abstract}

\section{Introduction}

The carob moth, Ectomyelois ceratoniae Zeller (Lep.: Pyralidae), is a major pest of pomegranate in Iran that causes quantitative and qualitative reduction of pomegranate yield in all cultivation regions of the country (Mozaffarian et al., 2007; Kishani Farahani et al., 2011, 2012a). In some years, this pest can cause yield losses of up to $80 \%$, and thus constitutes a major threat to the pomegranate industry in Iran (Shakeri, 2004; Kishani Farahani et al., 2011). Larval development and feeding by this pest inside the fruits protects them from insecticides and makes chemical control inefficient (Shakeri, 2004).

Correspondence: Lida Fekrat, Department of Plant Protection, Faculty of Agriculture, Ferdowsi University of Mashhad, Mashhad, Iran.

E-mail: fekrat@ferdowsi.um.ac.ir

Key words: parasitoid, carob moth, Ectomyelois ceratonia, pomegranate, olfactory responses.

Received for publication: 15 April 2014.

Revision received: 27 August 2014.

Accepted for publication: 4 September 2014.

(C) Copyright M. Aleosfoor et al., 2014

Licensee PAGEPress, Italy

Journal of Entomological and Acarological Research 2014; 46:3787

doi:10.4081/jear.2014.3787

This article is distributed under the terms of the Creative Commons Attribution Noncommercial License (by-nc 3.0) which permits any noncommercial use, distribution, and reproduction in any medium, provided the original author(s) and source are credited.
In Iran, collecting and destroying infected pomegranates at the end of the growth season is the most widely recommended control method for carob moth, as it eliminates overwintering sites (Behdad 1991; Mozaffarian et al., 2007). Removing flags (Shakeri, 2004), and staking the pomegranate fruit neck (Mirkarimi, 1996) are other common methods for removing the hatch sites. Currently, none of the conventional methods alone are able to control this pest (Shakeri, 2004).

Due to the developmental biology and behaviour of carob moth larvae, natural enemies could play a fundamental role in reducing the damage caused by this pest, and there appears to be much potential for employing various parasitoid species in biological control programs targeting it. Currently, several Hymenopterous species have been reported as larval parasitoids of carob moth (Gothilf, 1978; Kishani Farahani et al., 2011, 2012b). Goniozus legneri Gordh is one of the important natural enemies of Lepidopteran larvae on several crops, as it can develop successfully in Ectomyelois ceratonia larvae (Ehteshami et al., 2013; Legner et al., 1982; Zaviezo et al., 2007).

When considering the effectiveness of a natural enemy for pest population regulation, several attributes are crucially important, including the ability of a biological control agent to locate suitable host material. Parasitoid searching and host location behaviour is influenced by several external stimuli such as olfactory, visual, and tactile cues (Vinson, 1976, 1998; Broad \& Quicke, 2000; Graziosi \& Rieske, 2013).

Olfactory cues are used by many Hymenopteran parasitoids to orient to a potential host habitat as well as to a host, so odours play an essential role throughout the life span of the parasitoids. Olfactometers, in which the parasitoids can choose simultaneously among several different odours, are used to study and reveal responses of parasitoids to various odours (Vet et al., 1983; Vinson, 1981; Weseloh, 1981). In this study, a sixarm olfactometer was used to examine simultaneous cues by which females of this parasitoid species could locate larvae of the carob moth.

\section{Materials and methods}

\section{Insect rearing}

Carob moth larvae were separated from infested fruits originally collected from several pomegranate orchards in Fars province (Shiraz, Kavar, Estahban, Ij, Seyyedan, Faroogh) in the south of Iran. Ectomyelois ceratonia larvae were reared on artificial diet containing wheat flour (72\%), honey (12\%), glycerin (10\%), yeast (1\%), and distilled water, in transparent plastic jars $(20 \times 10 \times 10 \mathrm{~cm})$ at room temperature. The emerged adults from infested fruits were transferred into transparent jars $(18 \times 7 \mathrm{~cm})$ and provided with cotton wool soaked in $10 \%$ honey as a food source. 
For all experiments, 2-3-day old female Goniozus legneri adults were used. For rearing, Ephestia kuehniella (Lepidoptera: Noctuidae) caterpillars (third instar) were offered to a single mated female (4-7 days old) for $12 \mathrm{~h}$ in a plastic box (diam. $8 \mathrm{~cm}$, height $5 \mathrm{~cm}$ ) (Figure 1). The parasitised caterpillars were kept on a wheat germ-based artificial diet in an incubator $\left(25^{\circ} \mathrm{C}\right.$, L:D 16:8 h) until cocoon formation. Cocoons were kept in Petri dishes until adult emergence. Emerging adults were sexed and kept in cages $(20 \times 20 \times 20 \mathrm{~cm})$ in the same incubator at a sex ratio of $1: 2$ (male:female), with moist cotton wool and honey as a food source.

\section{Olfactometer design}

We designed a six-arm olfactometer for our experiments (Figure 2), which consisted of a central Petri dish with six arms extending from its sides. The arms had an internal diameter of $1 \mathrm{~cm}$. At the distal end of each arm, there was a Petri dish of $5 \mathrm{~cm}$ diameter. A small flow fan was connected to the Petri dishes using a bended tube to provide uniform airflow. Illumination was provided using two fluorescent lamps $40 \mathrm{~cm}$ above the olfactometer.

\section{Olfactometer experiments}

The adult parasitoids were 24 and $72 \mathrm{~h}$ days old and were tested individually. All female parasitoids were provided only with water from the time of emergence for the behavioural test, and had no contact with the test odour sources before the experiment. A maximum of 10 min was allowed for each parasitoid to make its final choice. After testing five insects, the whole apparatus was rotated $90^{\circ}$ and, after testing each parasitoid, cleaned with $95 \%$ ethanol.

To start a measurement, one female parasitoid was transferred from the cage to the central Petri dish using a 2.5-cm Teflon tube closed on one end by a nylon mesh. Carob moth frass, a healthy pomegranate, a carob moth larva, a carob moth larva+ artificial diet, and an Ephestia larva were tested for their attractiveness to the female parasitoids. The small fraction of females that did not enter the side arms within five minutes were considered non-responders and removed from the experiment.

To randomise possible side effects on the preferences of $G$. legneri, odour sources were renewed for each replicate and their positions alternated between replicates. Five replicates were performed on a given experimental day. One of the six side-Petri dishes was kept empty as a control in each replicate.

An odour source was considered attractive when a parasitoid exhibited a preference for it. The time for a parasitoid to initially cross the junction line into one arm was used to test whether a preference could be detected as soon as the female entered an arm, or whether she needed some exploration before displaying a preference. The preference

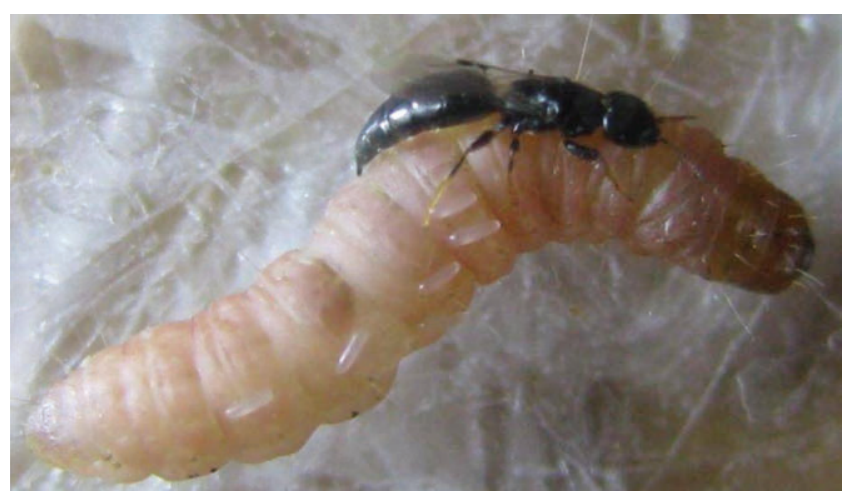

Figure 1. Goniozus legneri rearing on Ephestia kuehniella caterpillars. time was designated as the time it took for females to cross the junction line of each of the six lateral arms. Females were considered to have a lasting preference for an odour source when they spent significantly more time in one lateral arm than in the others.

\section{Statistics}

The data were normally distributed, so we performed one-way analysis of variance (ANOVA), with treatment differences separated using Fisher's least significant difference test at 5\% level of significance (SPSS Statistics ver. 21.0. Released 2012; IBM Corp., Armonk, NY, USA).

\section{Results}

We evaluated the absolute attractiveness of different odours, with air as a neutral control; there were significant differences among selection of various odour sources by parasitoids ( $\mathrm{F}=39.896, \mathrm{P}=0.000)$.

The parasitoids significantly more frequently selected the arm connected to frass of carob moth larvae compared with the other arms (Figure 3). There were no significant differences in preference among the three other choices: pomegranates, larvae+ artificial diet, and

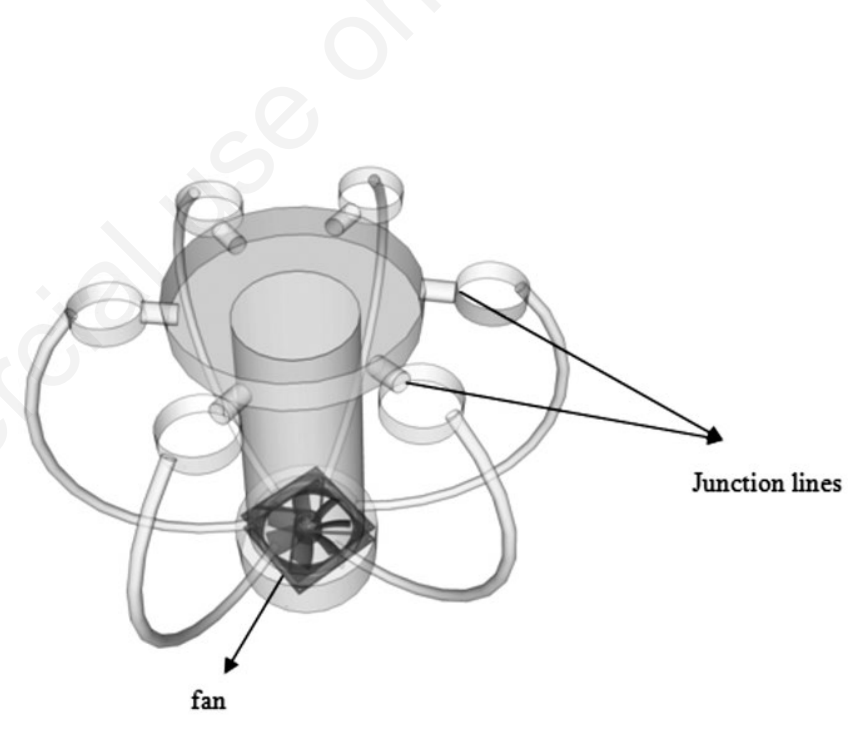

Figure 2. Six-arm olfactometer designed for this experiment.

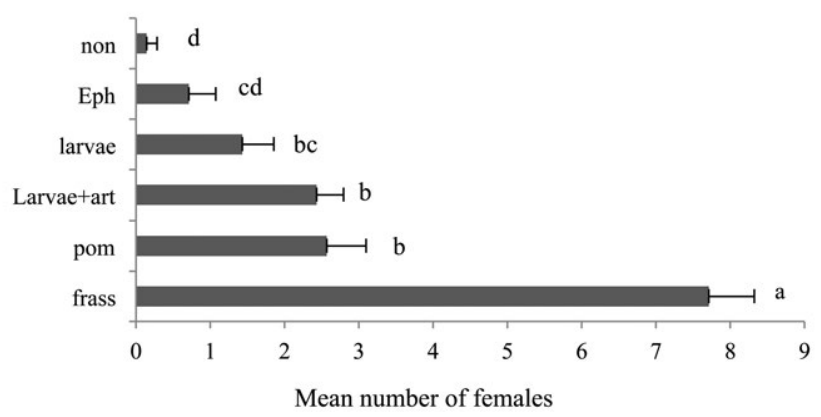

Figure 3. Mean number of females choosing each odour arm ( \pm standard error); different letters indicate significant differences at $5 \%$ significance level. 
Table 1. Mean preference time in parasitoid choice of each odour arm.

\begin{tabular}{cccccc} 
& Frass & Healthy pomegranate & Larvae+artificial diet & Larvae & Ephestia larvae \\
Mean \pm SE & $4.919 \pm 0.508^{\mathrm{a}}$ & $4.861 \pm 1.0571^{\mathrm{a}}$ & $3.335 \pm 0.938^{\mathrm{a}}$ & $5.902 \pm 1.098^{\mathrm{ab}}$ & $8.412 \pm 0.57 \mathrm{1}^{\mathrm{b}}$ \\
\hline
\end{tabular}

SE, standard error. a,bDifferent letters indicate significant differences at $5 \%$ significance level.

carob moth larvae. The parasitoids selected the Ephestia larvae and the control at lower frequencies; however, there were no significant differences between them (Figure 3).

There were significant differences among the preference times for the various odours $(\mathrm{F}=2.580 ; \mathrm{P}=0.047)$. The preference time for Ephestia larvae was significantly longer than those for other odours (Table 1). However, the difference between preference times of carob moth larvae and Ephestia larvae was not significant (Table 1).

\section{Discussion}

In spite of the breadth and complexity of the environment, parasitoids are able to find suitable hosts for their progeny (Cusumano et al., 2010). A good cue for parasitoids to use in finding their hosts is undoubtedly the signals they receive from their surrounding environments, such as the presence and quality of a host, or a sign of host feeding, such as host frass, if it is detectable over an appropriate distance (Vet \& Dicke, 1992; Hilker \& McNeil, 2007).

Several studies of behavioural responses of parasitoids using an olfactometer have been carried out to evaluate the attractiveness of different plant volatiles (Belz et al., 2012), parasitoid host- infested plants (Castelo et al., 2009), or sex pheromones of parasitoid hosts (Noldus, 1998). The aim of our study was to investigate the olfactory attractiveness of five different odour sources to $G$. legneri. This study demonstrated that $G$. legneri could show a behavioural response to the different odours.

All of the tested odours except that of Ephestia larvae were highly attractive when compared with air alone, both in terms of number of choices and preference time, although some were more attractive than others. Carob moth larval frass was the most attractive odour to the parasitoids; pomegranate fruits, carob moth larvae + artificial diet, and carob moth larvae were equally, but less attractive, and all were more attractive than the Ephestia larvae and the control. Ephestia larvae were the least attractive. These findings highlight the fact that the presence of carob moth larvae and their feeding signs, such as their frass, are important cues for parasitoids in identifying pomegranates that harbour carob moth larvae. According to our data, G. legneri wasps rely mainly on direct host-related cues, such as the presence of carob moth larvae or their frass, to locate their hosts. It is likely that the chemicals released by the host and/or its frass could be the cue that signals the searching female that the host is suitable for parasitism. However, further studies are needed to identify the chemical compounds that may account for these interactions.

Based on our results, $G$. legneri did not exploit volatiles produced by the Ephestia larvae, as no significant attraction was detected when these were tested. As the Ephestia larvae are not hosts of $G$. legneri in nature, the low attractiveness of Ephestia larvae compared with the other odours is not unexpected. This difference in preference suggests that $G$. legneri can discriminate among suitable and less suitable host insects by volatile signals, which would enhance their rate of successful parasitism and ensure a high survival ratio of their offspring. It is worth noting that the ability to find insect hosts using different signals implies a certain level of behavioural plasticity in the parasitoids.

\section{References}

BEHDAD E., 1991 - Pests of fruit crops in Iran. $2^{\text {nd }}$ ed. - Markaz-e-Nashre-Bahman, Tehran.

BELZ E., K LLIKER M., BALMER 0., 2012 - Olfactory attractiveness of flowering plants to the parasitoid Microplitis mediator: potential implications for biological control. - BioControl. 58: 163-173.

BROAD G.R., QUICKE D.I.J., 2000 - The adaptive significance of host location by vibrational sounding in parasitoid wasps. - Proc. R. soc. Lond. B Biol. Sci. 267: 2403-2409.

CASTELO M.K., NOUHUYS S.V., CORLEY J.C., 2009 - Olfactory attraction of the larval parasitoid, Hyposoter horticola, to plants infested with eggs of the host butterfly, Melitaea cinxia. - J. Insect Sci. 10: 1-16.

CUSUMANO A., GONZ LEZ J.M., COLAZZA S., VINSON S.B., 2010 Behavioral responses of the parasitoid Melittobia digitata to volatiles emitted by its natural and laboratory hosts. - Entomol. Exp. Appl. 136: 301-307.

EHTESHAMI F., ALEOSFOOR M., ALLAHYARI H., ALICHI M., 2013 - First record of Goniozus legneri (Hym.: Bethylidae), the larval ectoparasitoid of carob moth, in Iran. - J. Entomol. Soc. Iran 33: 89.

GOTHILF S., 1978 - Establishment of the imported parasite Pentalitomastix plethoricus (Hym.:Encyrtidae, on Ectomyelois ceratoniae (Lep.: Phycitidae) in Israel. - Entomophaga. 23: 299-302.

GRAZIOSI I., RIESKE L.K., 2013 - Response of Torymus sinensis, a parasitoid of the gallforming Dryocosmus kuriphilus, to olfactory and visual cues. - Biolog. Control. 67: 137-142.

HILKER M., MCNEIL J.N., 2007 - Chemical and behavioral ecology in insect parasitoids: how to behave optimally in a complex odorous environment?. In: WAJNBERG E.C., BERNSTEIN C.B., VAN ALPHEN J. (Eds), Behavioural ecology of insect parasitoids: from theoretical approaches to field applications. - Blackwell Publishing, Oxford: 92-112.

KISHANI FARAHANI H., BELL H., GOLDANSAZ S.H., 2012a - Biology of Apanteles myeloenta (Hymenoptera: Braconidae), a larval parasitoid of carob moth Ectomyelais ceratoniae (Lepidoptera: Pyralidae). - J. Asia Pacific Entomol. 15: 607-610.

KISHANI FARAHANI H., GOLDANSAZ S.H., SABAHI Q., 2012b - A survey on the over wintering larval parasitoids of Ectomyelois ceratoniae in three regions in Iran. - Crop Prot. 36: 52-57.

KISHANI FARAHANI H., GOLDANSAZ S.H., SABAHI Q., SHAKERI M., 2011 - A study on the larval parasitoids of carob moth, Ectomyelois ceratoniae in Varamin, Qom and Saveh. - J. Iranian Plant Prot. Soci. 41: 337-344.

LEGNER E.F., GORDH G., SILVERIA-GUIDO A., BADGLEY M.E., 1982 - New wasp may help control navel orangeworm. - California Agric. 36: 4-5.

MIRKARIMI A., 1996 -The effect of stuffing pomegranate fruit neck (calyx) on reduction of pomegranate neck worm Spectrobates (Ectomyelois) ceratoniae Zell. - Available from: http://iman.ut.ac.ir/ news/agr.htm

MOZAFFARIAN F., SARAFRAZI A., NOURI GANBALANI G., 2007 - Host plant-associated population variation in the carob moth Ectomyelois ceratoniae in Iran: A geometric morphometric analysis suggests a nutritional basis. - J. Insect Sci. 6: 1-11.

NOLDUS L.P.P.J.J., 1988 - Response of the egg parasitoid Trichogramma 
pretiosum to the sex pheromone of its host Heliothis zea. - Entomol Exp. Appl. 48: 293-300.

NAKAMUTA K., VAN TOL R.W.H., VISSER J.H., 2005 - An olfactometer for analyzing olfactory responses of death-feigning insects. - Appl. Entomol. Zool. 40: 173-175.

SHAKERI M., 2004 - Pests and diseases of pomegranate. - Tasbih publication. [In Farsi].

VET L.E.M., DICKE M., 1992 - Ecology of infochemical use by ntural enemies in a tritrophic context. - Annu. Rev. Entomol. 37: 141-172.

VET L.E.M., VAN LANTEREN J. C., HEYMANS M., MEELIS E., 1983 - An airflow olfactometer for measuring olfactory responses of hymenopterous parasitoids and other small insects. - Physiol. Entomol. 8: 97-106.
VINSON S.B., 1976 - Host selection by insect parasitoids. - Annu. Rev. Entomol. 21: 109-133.

VINSON S.B., 1981 - Habitat location. In: NORDLUND D.A., JONES R.L., LEWIS W.J. (Eds), Semiochemicals, their role in pest control. Wiley \& Sons, New York: 51-78.

VINSON S.B., 1998 - The general host section behavior of parasitoid Hymenoptera and a comparison of initial sterategies utilized by larvaphagous and oophagous species. - Biol. Control. 11: 79-96.

WESELOH R.M., 1981 - Host location by parasitoids. In: NORDLUND D.A., JONES R.L., LEWIS W.J. (Eds), Semiochemicals, their role in pest control. - Wiley \& Sons, New York: 79-95.

ZAVIEZO T., ROMERO A., CASTRO D., WAGNER A., 2007 - First record of Goniozus legneri (Hymenoptera: Bethylidae) in Chile. - Cien. Investig. Agr. 34: 49-52. 